\title{
JOINING OF POLYMER COMPOSITE MATERIALS
}

\author{
A Survey \\ Frank H. Magness \\ UCRL-ID--105662 \\ DE91 004946 \\ Mechanics of Materials Group \\ Engineering Science Division \\ Lawrence Livermore National Laboratory
}

\begin{abstract}
Under ideal conditions load bearing structures would be designed without joints, thus eliminating a source of added weight, complexity and weakness. In reality the need for accessibility, repair, and inspectability, added to the size limitations imposed by the manufacturing process and transportation/assembly requirements mean that some minimum number of joints will be required in most structures. The designer generally has two methods for joining fiber composite materials, adhesive bonding and mechanical fastening. As the use of thermoplastic materials increases, a third joining technique - w slding - will become more common. It is the purpose of this document to provide a review of the available sources pertinent to the design of joints in fiber composites. The primary emphasis is given to adhesive bonding and mechanical fastening with information coming from documentary sources as old as 1961 and as recent as 1989. A third, shorter section on composite welding is included in order to provide a relatively comprehensive treatment of the subject.
\end{abstract}

\section{DISCLAIMER}

\footnotetext{
This report was prepared as an account of work sponsored by an agency of the United States Government. Neither the United States Government nor any agency therenf, nor any of their employees, makes any warranty, express or implied, or assumes any legal liability or responsibility for the accuracy, completeness, or usefulness of any information, apparatus, product, or process disclosed, or represents that its use would not infringe privately owned rights. Reference herein to any specific commercial product, process, or service by trade name, trademark, manufacturer, or otherwise does not necessarily constitute or imply its endorsement, recommendation, or favoring by the United States Government or any agency thereof. The views and opinions of authors expressed herein do not necessarily state or reflect those of the United States Government or any agency thereof.
} 


\section{INTRGDUCTION}

The necessity for structurally sound, functionally reliable joints is an engineering design issue that considerably predates the evolution of modern fiber composite materials. The use of such materials in complex structures almost invariably produces a simpler design that requires fewer separate parts than an equivalent metal structure. As a result, a significant savings in weight is usually realized as well as a reduction in the number of joining operations and requisite assembly procedures, thereby enhancing reliability and lowering cost. Although the number of joints is frequently reduced, the requirement for joints is never eliminated.

The joining of metal structures is an established technology thai involves riveting, bolting, welding, glueing, brazing, soldering and other methods. By contrast, most polymer composites are amenable to either adhesive bonding or mechanical joining. More recently, effort and attention has been given to localized welding of thermoplastic composites. Adhesive bonding is generally preferred over mechanical fastening in light of the continuous connection that can be achieved. When drillirig holes for bolts or rivets, fibers or other reinforcements are cut, and large stıess concentrations occur at each discrete fastener hole. The necessity for removable parts in some assemblies and the need for interior access in others can only be addressed with mechanical fasteners. Thus adhesive bonding and mechanical fastening serve unique and essential functions in the joining of fiber composite materials.

Finally, the conflicts that inevitably arise in areas of rapidly evolving technology can be seen in the following comparison of composite joint design methodologies. Hart-Smith [1] states that the number of joints should be minimized, then specific design attention should be given to those joints that are most heavily loaded, subsequently filling in the gaps between joir.is by extending some of the layers at the splice. Vinson [2] recommends that structural components be designed in response to the loads and envirorments affecting those components without initial attention being given to joint requirements. Once issues such as fiber and matrix selection, stacking sequence, number of plies, etc. have been established, the design of the joints should be considered in detaii. While each of these approaches claims to have substantial emipirical support, it is apparent that agreement does not always exist, even at the most basic levels of design philosophy.

\section{References}

1. Hart-Smith, J., "Designing with Advanced Fibrous Composites," Workshop on New Materials and Process for Mechanical Design, May 1988, Brisbane, Australia.

2. Vinson, Jack R., "Mechanical Fastening of Polymer Composites," Polymer Engineering and Science, 29 (October 89). 


\section{ADHESIVE BONDING CF FIBER COMPOSITE MATERIALS}

The development of modern adhesives for the bonding of primary load bearing structures began several decades ago. The de Havilland Mosquito bomber of World War II was probably the first notable aviation application for adhesive bonding of composite materials i.e. plywood laminates and casein glue. Typical of the environmental issues of that time was the suitability of casein glue for the European theater but not for the temperature and humidity of the Far East. Later models used formaldehyde glues instead. In the United States, the Meltbond adhesives were developed by Narmco in the early 1940's for the Consolidated Vultec B-36 bomber.

The desirability of bonded joints in contrast to other techniques have been given by Kuno [1] as:

1. Often thinner gage materials can be used with attendant weight and cost savings.

2. The number of production parts can be reduced, and the design simplified.

3. The need for milling, machining and forming of details is reduced.

4. Large area bonds can be made by a minimum work force without special training.

5. Adhesive bonding provides a high strength to weight ratio with three times the shearing strength of riveted joints.

6. Improved aerodymic smoothness and visual appearance.

7. Use as a seal, and/or corrosion preventer when joining incompatible adherends.

8. Excellent electrical and thermal insulation.

9. Superior fatigue resistance. Adhesive bonded assemblies have shown a fatigue life twenty times better than riveted structures of identical parts.

10. Damping characteristics and noise reduction are superior to riveted assemblies.

11. Often, the adhesive is sufficiently flexible to allow for the variations in coefficients of thermal expansion when joining dissimilar materials.

While the advantages to using adhesive bonding are apparent, it is essential that there be methods to analyze, design and optimize adhesive bonded joints for many co.ifigurations subjected to numerous load conditions.

Kuno also points out that the use of adhesive bonding is increasing. For example, Cagle [2] indicates that approximately 14,000 square feet of adhesive are used in a Boeing 747.

\section{Adhesive Bonded Joint Technology}

\section{Single Lap Joint}

The single lap joint, shown in Figure $1 a$, has been studied more extensively than any other bonded configuration. Those evaluations include both experimental procedures as well as 
analytical, finite difference and finite element methods. For reference it is noted that the panels siown in Figuru la are the adherends joined together by an adherive.

Kutscha and Hofer [3] determined that single lap joints with adherends of unequal thickness have a maximum shear stress occuring at "the point where the load enters the joint from the thinner adherend." In a joint with identical adherends the stresses are symmetric about the bond mid-length.

Kutscha and Hofer's parametric studies provide a number of significant generalizations. 1) Adhesive stresses decrease with increasing specimen width, up to about $10 \mathrm{~cm}$. width, beyond which the stresses remain constant. Thus wider joints designed with strength data from $2.5 \mathrm{~cm}$ wide specimens would be conservative. 2) They found that maximum adhesive stresses do not decrease significantly with increased bonded area. 3) As the adhesive film thickness increases, more adhesive material is available to absorb the differential strains and hence the stresses decrease. As the adhesive shear modulus increases, 4) the maximum adhesive

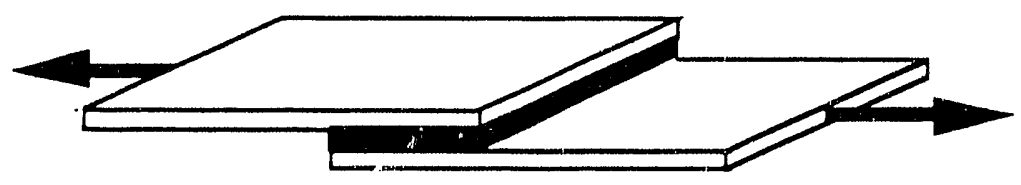

A. Single Lap Joint

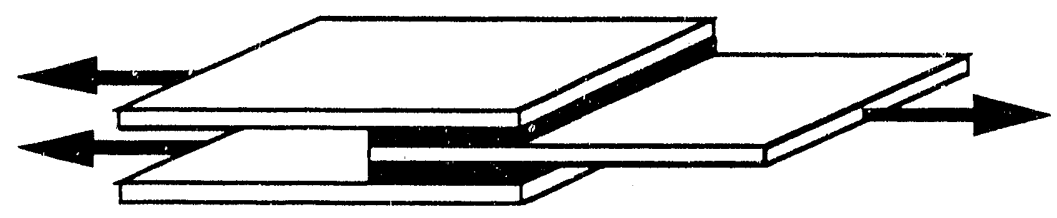

B. Double Lap Joint

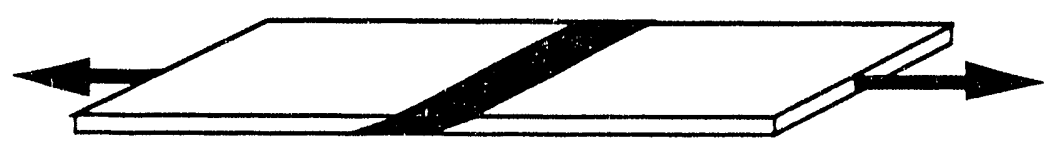

C. Scarf Joint

Figure 1. Bonded Joint Configurations

stresses increase almost linearly with the shear modulus (for values between $5(0,()()()$ and 250,000 psi, which is the conventional range for structural adhesives). 5) They also found that as the stiffness of the adherends increases, the resistance of the joint to bending increases and the maximum adhesive stiesses decrease. Finally, 6) maximum stresses in the adhesive are relatively insensitive to the value of the adherend Poisson's ratio. It is noted by the reviewer that these early conclusions and generalizations remain valid rolay. 
Kutscha and Hofer also defined a "joint efficiency" that continues to be applicable. It is defined for any bonded joint us the axial load divided by the nominal bonded area, divided by the strength of the weaker adherend without the joint, times 100 .

By way of conclusion, Kutscha and Hofer state that the best adhesive bonded joint design technique is an empirical approach starting with the development of shear strength joint data which is used as a guide for adhesive selection and proper overlap length, to a final step of building a full scale joint and testing it.

Lehman and Hawley [4] analyzed and compared several methods of adhesive bonding, including single lap (Fig. 1a), double lap (Fig 1b), scarf (Fig. 1c), stepped lap and various other adhesive joint configurations. They found that 1) the maximum joint strength occurs when the extensional stiffness of both adherends is the same; 2 ) fatigue runout (i.e. no failure before 10 million cycles) occurs when the maximum adhesive shear stress is below the proportional limit shear stress of the adhesive. 3) Adhesive shear stresses above the proportional limit cause fatigue cracks that propagate through the joint causing failure. They concluded 4) that the residual strength of the fatigue specimens that survive runout usually exceed the static strength values. Also, in bonded joints of epoxy resin composites where the bond length to thickness ratio exceeds 25,5 ) interlaminar shear strength of the adherends is the limiting strength of the joint. It was their considered opinion that semiempirical methods were the best approach to adhesive joint design.

Wang [5] concluded that bonded joints employing low modulus adhesives display better fatigue resistance than joints employing a higher modulus adhesive.

Hart-Smith [6,7] studied single lap joints involving a continuum model in which the adherends are elastic and the adhesive is elastic, perfectly plastic in shear while behaving elastically in transverse tension-compression. Among his conclusions were 1) that any adherend imbalance in properties causes a significant strength reduction in the joint, and 2) for thicker adherends the dominant failure mode is tensile peel stresses in the adhesive and the associated interlaminar stresses in the composite adherends. He emphasizes 3) the low structural efficiency of single lap joints, and suggests that they should not be employed without some support to react out the eccentricity. Finally, he states that 4) tough ductile adhesives produce much stronger joints than those adhesives which, although stronger, are more brittle.

\section{Double Lap Joints}

Lehman and Hawley were the first to show that double lap joints (Figure 1b.) were more than twice as strong as single lap joints of the same lap length due to the configuration symmetry, which reduces bending in the adherends and transverse (peel) stresses in the adhesive.

\section{$\underline{\text { Scarf Joints }}$}

The scarf joint is shown in Fig. 1c. The advantage of the scarf joint is aerodynamic smoothness; its disadvantage is the requirement for precise machining at a low angle in order to maintain a uniform bond thickness. Oplinger [8] states that the scarf joint provides efficient use of the overlap length by allowing the peak adhesive stresses to diminish as the overlap length increases. Hart-Smith [9] found that adhesive stresses will be uniform along the joint if both adherends have equal stiffnesses. For unmatched stiffnesses, the adhesive stresses will change monotonically over the length of the overlap. 


\section{Summary}

A significant consideration in analyzing and designing adhesive bonded joints is the adhesive material property characterization. Recently, Roy and Reddy (10) in a two dimensional finite element study, show the importance of modeling an adhesive in a bonded joint as a viscoelastic material. At high strain levels, nonlinear viscoelastic effects can produce creep strain significantly larger than the linear viscoelastic predictions. They also note significant changes in Poisson's ratio with time in some adhesives.

Rao and Gibson [11] have developed a torsional technique to measure the dynamic shear viscoelastic properties of thin film adhesives. It was found that for adhesive films greater than 0.04 in. thickness the adhesive behaved as the bulk polymer, but the properties do change for thinner films, based upon tests of one adhesive.

A few observations and comments that can be used as a preliminary guide to adhesive joint design.

1. Maximum shear stresses and normal stresses in the adhesive can be reduced by making the flexural stiffness and the extensional stiffness of the adherends as large as possible.

2. Regardless of the adherend materials, the flexural and extensional stiffnesses should be matched or the overall strength of the joint will be compromised.

3. There is a maximum bond length beyond which no additional load carrying capability is possible, because the peak shear and peel stresses do not diminish with additional length.

4. As the adhesive bond length increases, failure or yielding of the adherend becomes more probable.

Finally, it is noted that a comprehensive source of detailed and specific information regarding the design, evaluation and testing of adhesively bonded joints is contained in [12].

\section{References}

1. James K. Kuno, Structural Adhesives and Bonding, Proceedings of the Structural Adhesives Bonding Conference, El Segundo, CA (1979).

2. C. V. Cagle, Adhesive Bonding Techniques and Applications, McGraw-Hill (1968).

3. D. Kutscha and K. E. Hofer, Jr. "Feasability of Joining Advanced Composite Flight Vehicles," AFML-TR-68-391, (January 1969).

4. G. M. Lehman and A. V. Hawley, "Investigation of Joints in Advanced Fibrous Composites for Aircraft Structures," A.FFDL-TR-69-43, Vol. 1 (June 1969).

5. D. Y. Wang, "The Effect of Stress Distribution on the Fatigue Behavior of Adhesive Bonded Joints," ASD-TDR-63-93, AFML (July 1963).

6. L. J. Hart-Smith, "The Strength of Adhesive Bonded Single Lap Joints," Douglas Aircraft Company IRAD TR MDC-J0472 (April 1970). 
7. L. J. Hart-Smith, "Adhesive Bonded Single I aap Joints," NASA-CR 112230 (January 1973).

8. D. W. Oplinger, Proceedings of the Fourth Army Materials Technology Conference Advances in Joining Technology, September 1975.

9. L. J. Hart-Smith, "Adhesive-Bonded Scarf and Stepped Lap Joints," NASA CR 112237, January 1973.

10. S. Roy and J. N. Reddy, "Effects of Moisture Diffusion on Stress Distribution in Adhesive Joints," Advances in Adhesively Bonded Joints, ASME-MD-Vol. 6, pp. 17-22, 1988.

11. V. S. Rao and R. F. Gibson, "An Experimental Method for the Measurement of Dynamic Shear Properties of a Thin Film Adhesive," Advances in Adhesively Bonded Joints, ASME MD-Vol. 6, pp. 51-58, 1988.

12. Vinson, Jack R., "Adhesive Bonding of Polymer Composites," Polymer Engineering and Science, 29 (October 89).

13. Matthews, F. L., Joining Fibre-Reinforced Plastics, Elsevier Applied Science; London, UK (1987). 


\section{MECH.INICAL JOINING OF FIBCR COMPOSITE MAIERIALS}

The use of mechanical fasteners to join structural components is an area of engineering interest that has been developing since long before the advent of modern polymer composites. The immediate issue in the design of a mechanical fastener is to preclude a failure, which can occur in several ways as shown in Figure 2. Net tension and shear out failure are total structural failures in which the joined components are separated.

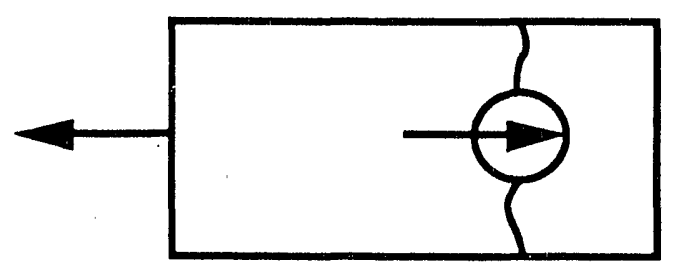

A. Net Tension

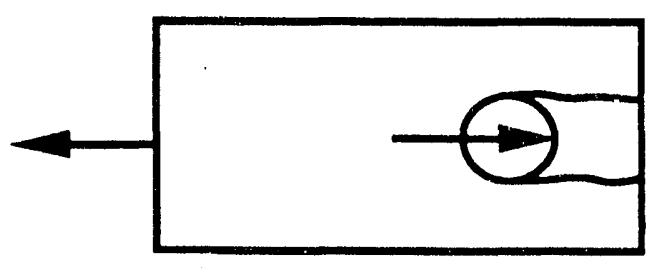

B. Shear Out

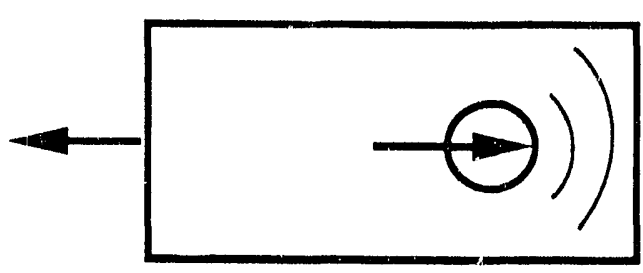

C. Bearing

Figure 2. Bolted Joint Failure Modes

Bearing failures however must be defined, such as relative structural displacement as a percentage of hole diameter, or some other measure. Such bearing failures may be influenced by whether the joint will be subjected to siatic loads or a vibratory spectrum of loads.

Kutscha and Hofer [1] presented one of the initial treatments of mechanical fasteners in composite structures. Th r study included empirically determined load distributions and 
joint strengths of fiberglass bolted joints and a comparison of that information with analytical solutions. They conclude that the failure modes are so different and complex that a semi-empirical method is the best approach to designing a bolted joint.

In a later study by Lehman and Hawley [2], single and double lap bolted joints were evaluated. They found that the single lap joints were not penalized greatly due to joint asymmetry. In the double lap joint, the use of bushings reduced the joint weight efficiency, which is generally considered unacceptable. However, the insertion of metal shims between laminae, and thickened panel end designs resulted in weight effective joints. Although more difficu't to fabricate, the shimmed joint produces a very compact, high strength joint.

Shearout failures were prevalent in all Lehman-Hawley bolted joints except for the shimreinforced and the bolted-bonded joints, even when the joint proportions were selected to produce bearing failures. Also, the use of whiskers as a resin matrix additive did not increase the joint strength.

Their testing indicated that an edge distance of 4.5 times the fastener diameter is required to achieve a balance between shear out and bearing failure. In these tests, net tension failures through fastener holes were precluded by a side distance of twice the fastener diameter. A laminate thickness to fastener diameter ratio of 0.8 resulted in maximum bearing strengths. Maximum shear strengths were developed in a laminate containing 0 and $+/-45^{\circ}$ layers in which $2 / 3$ of the laminate were $+/-45^{\circ}$ to the load axis.

Lehman and Hawley conclude that semi-empirical methods are the only effective approach to rational mechanical design in composite materials.

Cruse, Waszczak and Konish [3] focused on the effects of sharp cracks and loaded holes on the strength of composite material structures. They evaluated the strength of bolted joints in boron and graphite epoxy plates and then made predictions reqarding fracture in advanced composite materials. Among their conclusions was the determination that linear elastic fracture mechanics could be employed if factors such as a lower bound on critical crack length and the material property dependence on finite plate dimensions can be determined.

In May 1974, Oplinger and Gandhi [4] conducted an analytical investigation of the elastic response and failure of mechanically fastened orthotropic panels with either single or multiple fasteners. An interactive approach was used to accurately determine the arc of contact, a non-linear aspect of the problem. They studied joints involving a single pin, a periodic array of fasteners in finite ractangular plates, and an isolated pin in an infinite plate. They found that an optimum value of $s / d=2$ corresponds to a minimum of the atio of peak net tension stress to average applied stress, where $2 \mathrm{~s}$ is the distance between pin center lines.

Also in 1974, Van Siclen [5] documented the design procedures for bolted joints in graphite epoxy laminates. His approach was to obtain and evaluate actual jcint test data, and from the data he established semi-empirical procedures for predicting joint strength as a function of all the pertinent variables.

He discussed each of the geometric parameters affecting joint behavior which are: edge distance (e), side distance (s), hole diameter (d), and laminate thickness. A discussion of the pertinent laminate properties including fiber orientation, stacking sequence and types of material systems. 
Van Siclen also evaluated various reinforcing concepts including matallic interleaves, externally bonded-on metallic doubles, laminate crossply buildups, and fiberglass "softening strips."

He also pointed out the significance of specific fastener configuration. For example, the use of a countersunk fasiener in place of a protruding head design will severely comprornise the bearing strength of a joint.

Van Siclen states that the net tensile load, $\mathrm{P}_{\mathrm{NT}}$, that a given joint can carry, is given simply by

$$
P_{N T}=F_{N T}(2 s-d) t
$$

where $\mathrm{F}_{\mathrm{NT}}$, the net tension strength is determined experimentally as functions of the side distance ratio, s/d, and the edge distance ratio, e/d.

For shear out failure load, $\mathrm{P}_{\mathrm{SO}}$, the simple equation to use is

$$
P_{S O}=F_{S O}(2 s-d) t
$$

where $F_{S O}$, the shear out strength is determined experimentally as a linear function of the edge distance ratio, e/d, only.

For the allowable bearing load, $P_{B R}$, the equation to use is

$$
\mathrm{P}_{\mathrm{BR}}=\mathrm{F}_{\mathrm{BRU}} \mathrm{dt}
$$

where $F_{\mathrm{BRU}}$ is the ultimate bearing strength of the laminate determined experimentally, and is strictly a function of the stacking sequence of the laminate.

Failures in net tension and shear out are obvious. For bearing failure a definition for that failure must be made, for example, a limit to hole growth as some fraction of hole diameter.

As opposed to Lehman and Hawley, Van Siclen found that the allowable shear out strength for a $(0,+/-45,90)$ graphite epoxy laminate is significantly reduced as the e/d ratio is increased. He found that for $\mathrm{e} / \mathrm{d}>4$, bearing becomes the mode of failure, a conclusion that differed from the Air Force Design Guide.

Van Siclen determined, as did Lehman and Hawley, that the minimum weight reinforcing approach is to use $+/-45^{\circ}$ plies in the joint area. For minimum panel thickness, the use of internally bonded titanium interleaves was the best approach.

At an AMMRC Symposium in 1974, Oplinger and Gandhi [6] presented results from their continuing analyses. They concluded that the optimum fastener spacing is $\mathrm{s} / \mathrm{d}=1$, and that full joint strength is developed when $\mathrm{e} / \mathrm{d}>2$. The latter differs from Lehman and Hawley. One of their more significant results indicates that the differences between single and mutiple pin configurations is minimal for commonly encountered laminates such as $\left(0_{2},+/-\right.$ $45)$ configurations. In unidirectional laminates, however, fastener interactions are important.

Also in 1974, Whitney and Nuismer [7] developed an important model for failure criterion in laminates involving bolted joints. Their models assumed that failure occurs in a notched 
laminate when a critical stress state is reached at or within a characteristic distance away from the notch. This distance is assumed to be a material parameter independent of the laminate stacking sequence and the stress distribution. Once this distance is calculated from empirical data, it is villid for other notches and stacking sequences. Subsequent to the initial publication, Pipes, Gillespie and Wetherhold [8] have found that this characteristic distance is dependent on hole size and a variety of other variables. In 1985 Awerbuch and Madhukar [9] recommend, after an extensive review of the literature, that the characteristic distance parameter be determined experimentally for each material and stacking sequence.

Using a characteristic distance is empirical, but many feel it has the inherent ability to reflect the failure characteristics of a material. All that is required to make predictions for bolted joint failures is a linear stress analysis and the characteristic failure distance for that material and stacking sequence.

In January 1976, Stockdale and Matthews [10] demonstrated that ultimate bearing loads are increased by 40 to 100 percent in glass reinforced laminates by increasing the clamping pressure of a bolt. They also measured the contributions of the washers transferring load through surface friction.

Quinn and Matthews [11] studied the effects of stacking sequences on pin bearing strengths using 0,90 and $+/-45^{\circ}$ plies in eight different sequences. They found that placing $90^{\circ}$ plies at or next to the outer surfaces increases the bearing strength. Also, the ultimate failure mode was dependent upon stacking sequence. The [90/45/0] s layup was found to have the highest strength, and was $30 \%$ stronger than the weakest layup, which was $[0 / 90 / 45]_{s}$.

Allred [12] showed in 1977 that Kevlar reinforced composites would cause problems when they were subjected to bearing loads in bolted joints. He stated that it is desirable to obtain not only the ultimate values of bearing load, but also the entire load-deflection curve, because the material "yield strength" from such a curve provides a better design allowable than the ultimate bearing strength so often used, particularly when the structure is subjected to repeated loading. He found that the quasi-isotropic configuration exhibited the highest yield strength of all those he tested. Finally, Allred recommends local reinforcement when designing a Kevlar composite component.

In 1979, Hyer and Lightfoot [13] evaluated the effect of hole size on the strength of bolted joints, and concluded with others that increased hole size reduces the strength of the joint.

Prior to 1982 only one analytical evaluation, published by Matthews, Wong and Chryssafitis [14], had considered the important effects of lateral bolt pressure around the hole. A finite element analysis using 20-node brick elements and 3D effective laminate properties was conducted to determine through thickness stresses. Three conditions were studied: pin, finger tight washer and fully tight washer. Their results showed that pin loaded holes have tensile, through thickness stresses of 0.065 times the bearing stresses. When a finger tight constrint is applied (a surface displacement is imposed without lateral pressure), the out of plane tensile forces are negated by compressive forces built up ahead of the bolt. A very significant result was found for the fully constrained case (surface displacements specified), high interlaminar shear stresses occur near the surface, ahead of the washer. This agrees with recent experimental observations that bearing failure can occur ahead of the washer.

Considerable differences in bearing strengths of composites using two different epoxy matrix materials was reported by Kretsis and Matthews [15] in 1985. This certainly gives emphasis to the empirical considerations necessary for designing and/or analyzing tolted 
joints. Matthews and Kalkanis also investigated the effects of lateral constraint on Kevlar fabric composite bolted joints.

Jurf [16] in 1986 completed an inclusive study of the behavior of bolted joints in composite laminates. His first objective was to experimentally determine the relationships between joint strength and various geometric patterns, and to determine how these relationships are influenced by the degree of lateral surface constraint. Kevlar epoxy and graphit. epoxy $[0 /+45 / 90 /-45]_{2 s}$ laminates were employed.

Jurf's second objective was to predict the observed experimental results using only the material lamina properties and the laminate stacking sequence. This utilized a nonlinear laminate sequence and incorporated the effective properties into a multilinear elastic plastic finite element analysis.

Some of the experimental results include:

1) Bearing strength increases with respect to $\mathrm{s} / \mathrm{d}$ or e/d ratio independent of lateral constraint, and the joints fail catastrophically in net tension or shear out respectively.

2) Bearing strength demonstrates a hole size dependence, independent of lateral constraint, that is analogous to the notched strength of tensile samples with centrally located holes.

3) Bearing strength increases with laminate thickness until it gradually reaches a level where it becomes constant, again, independent of the lateral constraint.

4) For a specified torque, bearing strength increases with washer diameter where failure occurs ahead of the washer, as washer diameter becomes larger, a greater percentage of failure occurs ahead of the bolt.

5) The effects of lateral constraint pertain largely to bearing failures; net tension failure and shear out failure show little dependence on lateral constraint.

6) There is an approximately two fold increase in bearing strength from pin joint to finger tight bolting because the out of plane failure mechanisms are suppressed.

7) The bearing strength increases with applied torque mostly by frictional forces carried between the bolt washer and the laminate surface.

\section{Summary}

The design of bolted joints for fiber composite materials is a complex endeavor that requires an empirical approach in order to yield a safe and efficient joint. It is the purpose of this document to provide general insight into the issues that influence joint performance and to offer some basic guidelines for making design decisions.

The following general approach is provided for information and reference. First the structural components to be joined should be designed by the loads and environment on those components, not by the joint requirements. Stated another way, if two structural components are to be mechanically joined, the tibers, matrices, fiber volume fractions, stacking sequence, number of plies, etc. in those structural components should all be 
determined by the loads, temperatures and humidity acting on the structure - not by requirements set by the mechanical joint.

Having determined the above, the joint can then be studied in detail. The variables to be considered include: bolt diameter; number, configuration and spacing of the bolts, type of bolt (countersunk, flathead, etc.), washers, applied torque, edge distance constraints, side distance constraints and any other restraint imposed by the overall structural system.

At this point, whatever test data is available from any scurce should be used to make an initial design of the joint for the already specified composite structures to be joined. Thus a preliminary design has been established based on the best available information to select bolt material, diameter, spacing, edge distance, applicd torque and size of washers.

For that preliminary design, full scale test programs must be conducted on single (or multipli) fartener test pieces to obtain the net tension failure strength as functions of the side distance to bolt diameter ratio $(\mathrm{s} / \mathrm{d})$. Other tests must be conducted to obtain the shearout failure strength as a function of the edge distance to bolt diameter (e/d). Finally, for the composite components to he joined, tests must be conducted to obtain the bearing strength. Enough duplicate tests must be conducted to obtain a statistically valid set of data. The result will be an accumulation of strength data for use in the design equations listed earlier. Thus, the Van Siclen approach to joint design is recommended. However, if the Whitney, Nuismer, et al. approach is followed, suitable tests must be conducted to obtain the necessary material constants.

With all of this, a final design can be made. Unless there are some geometric restrictions, a design can be found in which, from the data obtained above, net tension failure, shearout and bearing failure can occur simultaneously at the same load. If there are some restrictions on edge or side distances, then such an optimization is not possible, and one failure mode will predominate.

If other bolts, bolt diameters, washer size:, etc. are to be considered then the above test procedure needs to be repeated, and a decision for the final design made.

\section{References}

1. D. Kutscha and K. E. Hofer, Jr., "Feasibility of Joining Advanced Composite Flight Vehicles," AFML-TR-68-391, (January 1969).

2. G. M. Lehman and A. V. Hawley, "Investigation of Joints in Advanced Fibrous Composites for Aircraft Structure," AFFDL-TR-69-43, Vol. 1 (June 1969).

3. T. A. Cruse, H. J. Konish and J. P. Wasczak, Proceedings of the Colloquium on Structural Reliatility: The Impact of Advanced Materials on Engineering Design, edited by J. L. Swedlow, T. A. Cruse and J. C. Halpin, pp. 222-236 (CarnegieMellon University), 1972.

4. D. W. Oplinger and K. R. Gandhi, Proceedings of the 2 nd Conference on Fibers. Composites and Flight Vehicle Design, pp. 811-842. AFFDL-TR-74-1()3, September 1974. 
5. R. C. Van Siclen, Proceedings of the Army Symposium on Sol;id Mechanics (AD 786 543), pp120-138 September 1974.

6. D. W. Oplinger and K. R. Gandhi, "Analytical Studies of Structural Performance in Mechanically Fastened Fiber Reinforced Places," Proceedings of the Army Symposium on Solid Mechanics (AD 786 543) AMMRC-MS 74-8, fp 21 1-240 September 1974.

7. J. M. Whitney and R. J. Nuismer, J. Compos. Niater., 8, 253 (1974)

8. R. B. Pipes, J. W. Gillespie, and R. C. Wetherhold, Polym. Eng. Sci., 19, 1151 (1979).

9. J. Awerbuch and M. S. Madhukar, J. Reinforced Plast. Compos. 4, (Jan. 1.985).

10. J. H. Stockdale and F. L. Matthews, Compnsites, 34, (Jan. 1976).

11. W. J. Quinn and F. L. Matthews, J. Compos. Mater., 11, 139 (April 1977).

12. R. E. Allred, "The Behaviour of Kevlar 49 Fabric/Epoxy Laminates Subjected to Pin Bearing Loads," Sandia Laboratories Report SAND 77-0347, April 1977.

13. M. W. Hyer and M. C. Lightfoot, "Ultimate Strength of High Load Capacity Composite Bolted Joints," Composite Materials - Testing and Design, ASTM STP 674, pp118-136 (1979).

14. F. L. Matthews, C. M. Wong and S. Chyssafitis, Composites, 316 (1982).

15. G. Kretsis and F. L. Matthews, Composites, 16, 92 (1985).

16. R. A. Jurf, Doctoral Dissertation. Department of Mechanical Engineering, University' of Delaware, Dec. 1986.

17. Vinson, Jack R., "Mechanical Fastening of Polymer Composites," Polymer Engineering and Science, 29 (October 89).

18. Matthews, F. L., Joining Fibre-Reinforced Plastics, Elsevier Applied Science; London, UK (1987). 


\section{WELDING OF THERMOPLASTIC MATERIALS}

Welding, as it applies to a fiber composite material, involves the sequential melting and resolidification of materials at a joint or interface, and is therefore limited to thermoset fiber composites. Welding methods can be broadly classified with regard to the heat source as 1) thermal bonding, comprising hot gas welding, extrusion welding, hot tool welding, and infrared heating, 2) friction (mechanical) welding, comprising spin welding, angular vibration welding, orbital welding, vibration welding and ultrasonic welding, and 3) electromagnetic bonding, which includes resistance (implant) welding, induction ivelding, dielectric heating, and microwave heating.

\section{Thermal Bonding}

\section{Hot Gas Welding}

In the hot gas welding method a thermoplastic filler rod and the parts to $b_{1}$; joined are heated by a hot gas st eam. In this respect it is similar to gas welding of metals, but in contrast to metal welding, the filler rod is not melted. Rather, the rod is pushed into the joint and heated until it softens sufficiently to fuse with the workpicee. it is possible to automate this process.

The mai. advantage of hot-gas welding is its flexibility. Simple, portable equipment can be used for fabricating large, complex one-of-a-kind parts, or for carrying out repairs of thermoplastic parts. It is a slow process that is difficult to control, especially in the commonly used manual mode, and is not well-suited for mass production.

\section{Hot-Tool Welding}

In the hot-tool welding process, the surfaces to be joined are brought to the "melting" temperature by direct contact with the matching surfaces of a heated metallic tool. The molten surfaces are then brought together, and the interface is allowed to cool and solidify under controlled pressure, resulting in a weld. In many applications, such as the joining of plastic pipes, the surfaces to be joined are flat, so the hot tool is essentially a hot plate. However, in a number of applications, such as automotive headlamps and rear lights, the doubly-curved joint interface surface requires complex tools that allow the hot surfaces to match the contours of the two halves to be joined. The applicability of this process to complex joint geometries is one of the major advantages of this process.

\section{Friction Welding}

\section{Spin Welding}

Also called friction welding, this method can be used for joining components along plane, circular mating surfaces. The parts to be joined are rotationally rubbed relative to each other, under pressure, about an axis normal to the contact plane. The resulting frictional heating at the plane iriterface causes the plastic to heat and melt. When the relative motion is stopped, the molten film solidifies under pressure, resulting in a weld.

\section{Vibration Welding}

In vibration welding, also called linear welding and linear frict on welding, frictional work done by vibrating two parts, under pressure, along their common interface is used to 
generate heat to effect a weld. This process is ideally suited to the welding of thermoplastic parts along relatively flat seams. It is also possible to vibration weld parts with a small outof-plane curvature.

\section{Ultrasonic Welding}

High-frequency (20 to $50 \mathrm{kHz}$ ), low amplitude (0.0005 to .0025 in.) mechanical vibrations are imposed to create localized heating to effect welds in thermoplastic materials. The parts to be joined are held together under pressure and then subjected to ultrasonic vibrations. Although the precise mechanisms causing localized heating are not well understood, heat generation is believed to occur by a combination of surface and intermolecular friction.

\section{Electromagnetic Bonding}

\section{Resistance (Implant) Welding}

In this process an electrically conductive wire or braid is placed within the joint interface and resistively heated by the passage of an electrical current. The heat causes the surrounding plastic to melt, and a weld is effected by subsequent cooling. The metal wire or braid remains within the joint, and can therefore affect its strength. The use of such inserts also increases the overall cost. The main advantage of this process is its simplicity and its applicability to complex joints in large parts. Weld times are short, less than 30 seconds even for the largest parts.

\section{Induction Welding}

Induction welding is an important variant of implant welding in which a ferromagnetic implant is induction-heated by a high-frequency electromagnetic field. In early versions of this process a sacrificial metallic implant was inserted in the joint area. During the welding process the joint was pressurized and the metallic insert heated by an RF field with a frequency in the range of 200 to $500 \mathrm{kHz}$. Melting and subsequent solidification of the plastic around the insert resulted in the weld. Plastics are not affected by RF electromagnetic fields in this frequency range.

\section{Summary}

In addition to mechanical fastening and adhesive bonding, which can be used for joining all materials, an array of welding methods can be used for joining thermoplastic composite parts. Although these methods have been in use for over 25 years, they are neither well characterized nor well understood. Very little is known about the effect of process parameters on the static strengths of welded joints in plastics and plastic joints. This will have to change if joining is to become an integral part of assembly techniques for plastic parts used in structural applications.

\section{References}

1. J. A. Neumann and F. J. Bockhoff, Welding of Plastics, Reinhold Publishing Corporation, New York (1959). 
2. M. G. Dodin, "Welding Mechanisms of Plastics: A Review," Journal of Adhesion, 12, 99-111 (1981).

3. M. N. Watson, R. M. Rivett, and K. I. Johnson, "Plastics - an Industrial and Literature Survey of Joining Techniques," The Welding Institute Report No. 7846.01/85/471.3, Abington, UK (1986).

4. M. N. Watson, "Welding Plastics: A Primer," Automotive Engineering, 94, 55-61 (1986).

5. M. N. Watson and S. B. Jones, "Welding Techniques for Plastics," Metals and Materials (Inst. Met.), 3, 581-585 (1987).

6. Anonymous, several articles in "1988 Fastening, Joining \& Assembly Reference Issue," Machine Design (November 1988). 


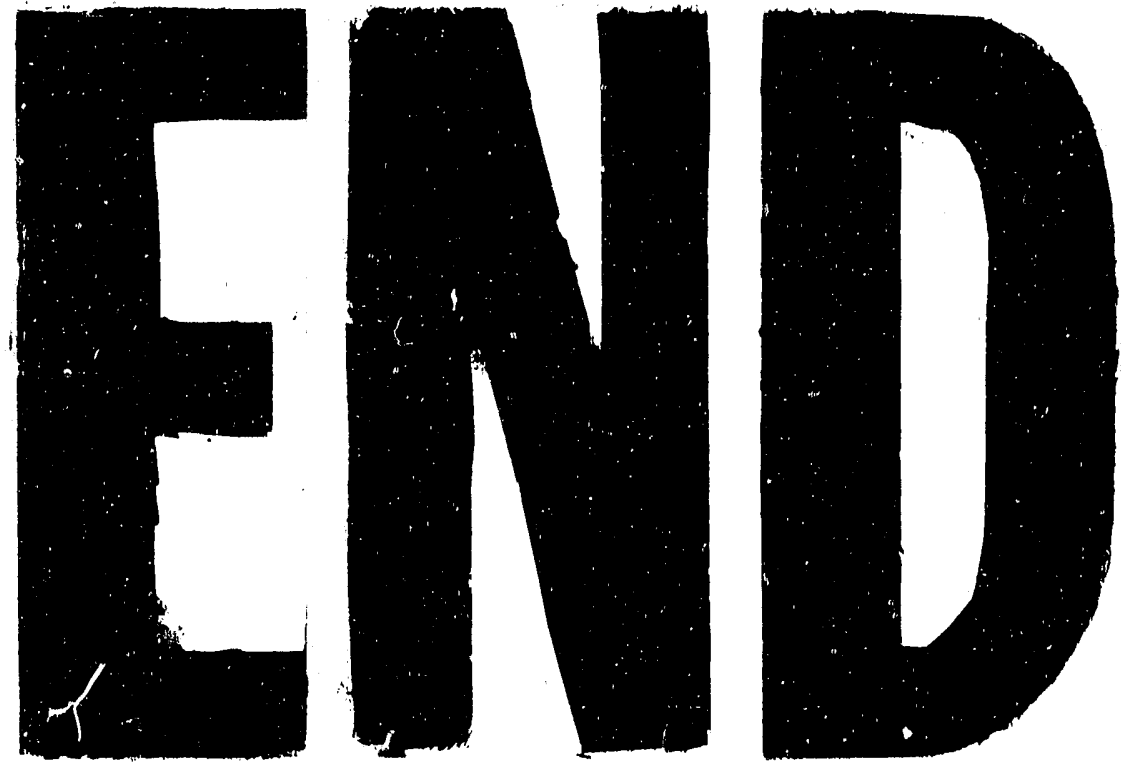

4
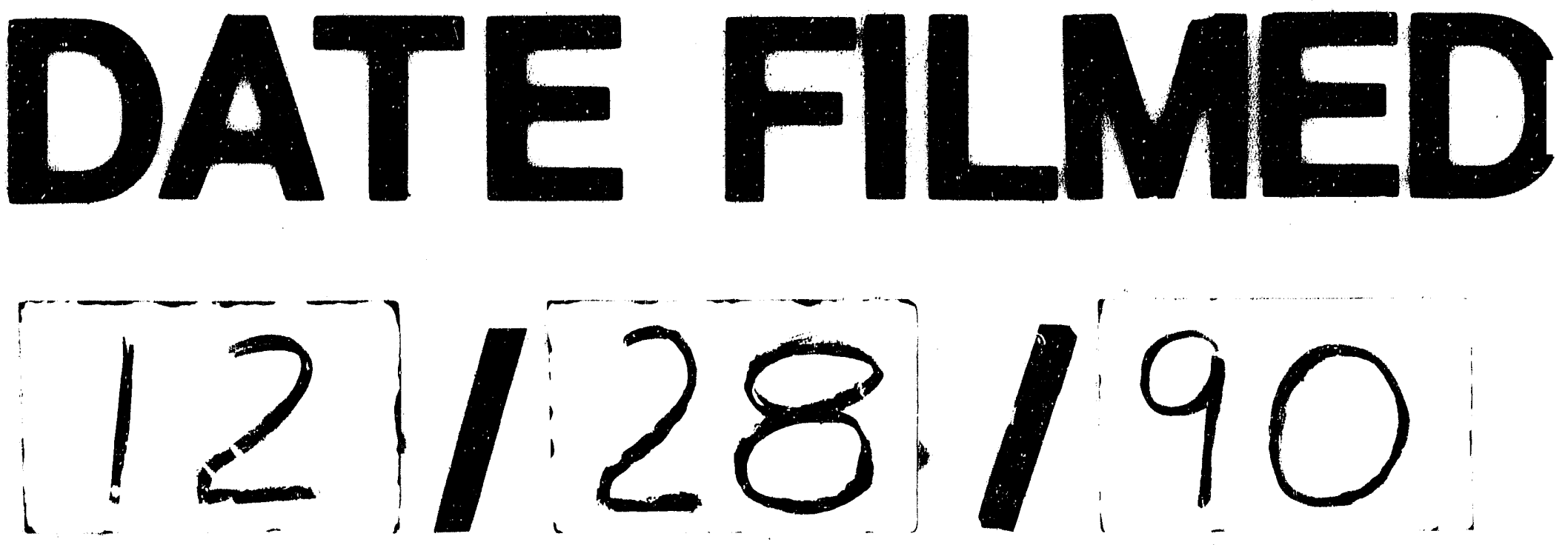
